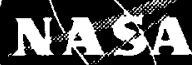

An Incidence Loss Model for Wave Rotors With Axially Aligned Passages

Daniel E. Paxson

Lewis Research Center, Cleveland, Ohio

Prepared for the 34th Joint Propulsion Conference cosponsored by AIAA, ASME, SAE, and ASEE Cleveland, Ohio, July 12-15, 1998

National Aeronautics and Space Administration

Lewis Research Center 
Available from

NASA Center for Aerospace Information 7121 Standard Drive

Hanover, MD 21076

Price Code: A03
National Technical Information Service 5287 Port Royal Road Springfield, VA 22100 Price Code: A03 
AIAA-98-3251

\title{
AN INCIDENCE LOSS MODEL FOR WAVE ROTORS WITH AXIALLY ALIGNED PASSAGES
}

\author{
Daniel E. Paxson ${ }^{\dagger}$ \\ NASA Lewis Research Center \\ Cleveland, Ohio, USA
}

\begin{abstract}
A simple mathematical model is described to account for the losses incurred when the flow in the duct (port) of a wave rotor is not aligned with the passages. The model, specifically for wave rotors with axially aligned passages, describes a loss mechanism which is sensitive to incident flow angle and Mach number. Implementation of the model in a one-dimensional CFD based wave rotor simulation is presented. Comparisons with limited experimental results are consistent with the model. Sensitivity studies are presented which highlight the significance of the incidence loss relative to other loss mechanisms in the wave rotor.
\end{abstract}

\section{Introduction}

Inlet flowfields of nearly any wave rotor typically contain significant velocity non-uniformities. This is true for both on and off-design operation. The nonuniformities arise from, among other causes, mis-timed waves in the passages, and reflected expansion waves of finite width. From the reference frame of the rotor passages, the non-uniformities result in inflow incidence angles which can be severe, and can in turn result in large relative total pressure losses. Despite the large losses in the relative frame however, incidence can result in work being done on (or by) the entering flow, which can affect the overall performance of the machine. Thus, accurate predictions of wave rotor performance requires adequate accounting of these effects. In the case of two and three-dimensional unsteady CFD calculations they are computed directly. ${ }^{1}$ For unsteady one-dimensional, and steady twodimensional calculations however, they must be modeled. ${ }^{2-4}$ Unfortunately, little has been found in the literature, either theoretical or experimental, to shed light on an appropriate modeling approach.

This paper presents a model which has been implemented in a one-dimensional CFD based wave rotor simulation ${ }^{4}$. It applies specifically to wave rotor configurations in which the passages are aligned with

\footnotetext{
${ }^{\dagger}$ Member AIAA

Copyright 1998 by the American Institute of Aeronautics and Astronautics, Inc. No copyright is asserted in the United States under Tite 17, U.S. Code. The U.S. Government has a royalty-free license to exercise all rights under the copyright claimed herein for Governmental Purposes. All other rights are reserved by the copyright owner.
}

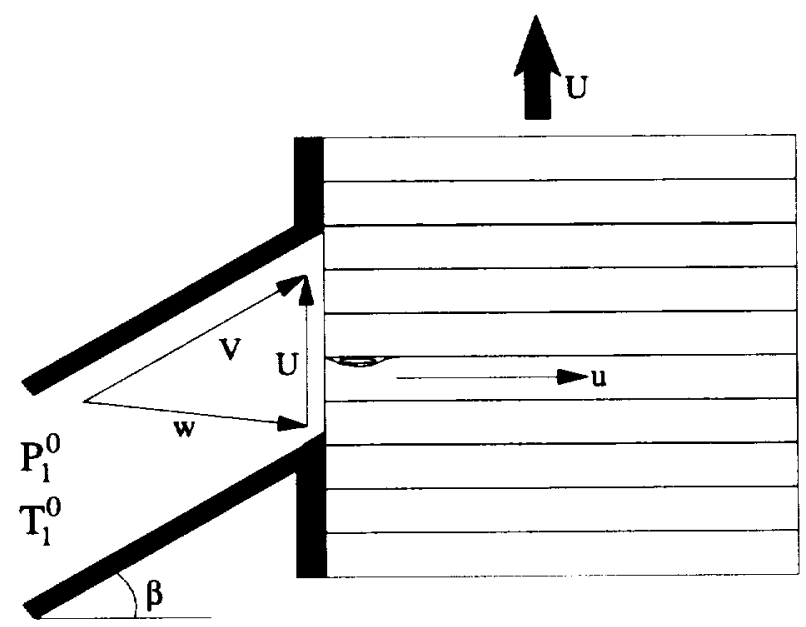

Figure 1 Incidence Flow Schematic

the axis of rotation (e.g. pressure exchange machines); however, it could be modified to include more general configurations. It produces realistic loss estimates over a wide range of incidence angles, at low to moderate incident Mach numbers. The model and its implementation are described. Comparisons are then made between simulated data and those from the NASA Lewis 3-port wave rotor experiment ${ }^{5}$. These include both limited dynamic pressure traces within a wave rotor passage in a high incidence region of a wave rotor flowfield, and averaged port performance data. The relative significance of incidence losses are then compared to other (modeled) loss mechanisms by way of simulated performance maps with various models 'turned on' or 'off'. The results will show that incidence losses can be at least as significant as other major losses such as those due to finite passage opening time, leakage, or friction.

\section{Model Description}

A schematic diagram of the envisaged flowfield, along with relevant nomenclature is shown in Fig. 1. It is shown again in Fig. 2 from the reference frame of a passage. Flow entering the passage at incidence forms a separated region, or vena contracta. The flow then reattaches downstream having lost relative total pressure (momentum) primarily due to the shear stress at the boundary between recirculating, separated flow 


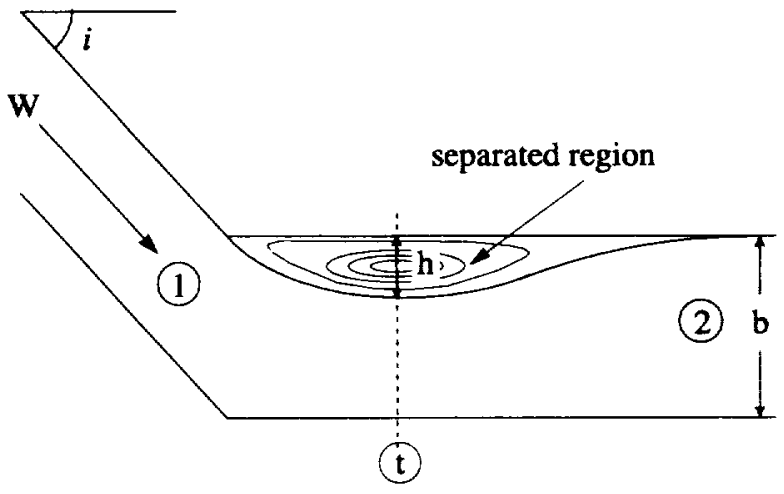

Figure 2 Incidence Flow Schematic From Passage Perspective

and that which passes directly through.

To estimate the total pressure loss, several simplifications are made. First, the flow to the left of plane $t$ in Fig. 2 and outside the separated region is assumed isentropic. Second, the flow in plane $t$, but outside the separated region, as well as the flow in region 2 is assumed parallel to the passage. Third, the static pressure in plane $t$ is constant, and there is no net velocity in the separated region. These assumptions imply that the losses are kinematically equivalent to those of a backward facing step of height $h$ shown in Fig. 2. The gas is also assumed calorically perfect.

The maximum height of the separated region $h$ is considered a function the incidence angle $i$. The particular choice of this functionality used in the present model is based upon a low speed (e.g. incompressible) incidence loss model which may be written as

$$
\Delta \mathrm{P}_{1-2}^{0}=\sin ^{2}(\mathrm{i}) \frac{1}{2} \rho \mathrm{w}^{2}
$$

where $w$ is the relative velocity in Fig. 2. This relation, suggested by Roelke ${ }^{6}$ arises from the assumption that all of the kinetic energy in region 1 which is normal to the passage of region 2 is lost at constant mean static pressure.

Using Eqn. 1, the assumptions described above, and the incompressible equations of mass and momentum from plane $t$ to region 2 , the following relationship for $h$ is obtained

$$
\frac{h}{b}=\frac{|\sin (i)|}{|\sin (i)|+\cos (i)}
$$

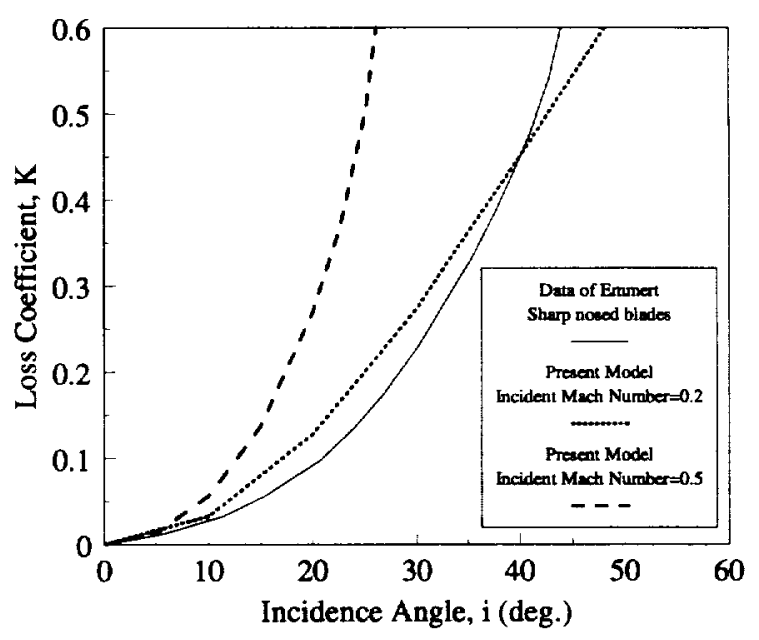

Figure 3 Experimental vs. Modeled Loss Coefícients for a Sharp Nosed Turbine Cascade.

where $b$ is the passage height shown in Fig. 2. Using the nomenclature of Fig. 1, this may be rewritten as

$$
\frac{h}{b}=\frac{|V \sin (\beta)-U|}{|V \sin (\beta)-U|+V \cos (\beta)}
$$

Where $V$ is the absolute velocity upstream and $U$ is the rotor speed. Of course, since Eqn. 3 is derived from Eqn. 1 it will yield the same total pressure loss. Equation 1 has simply been reinterpreted; however, it is strictly incompressible. Compressibility effects may be included by assuming that Eqn. 3 remains valid; however, the mixing calculation from the throat region, $t$ to region 2 now becomes a compressible mass momentum and energy balance, namely

$$
\begin{aligned}
& \rho_{\mathrm{t}} w_{\mathrm{t}}\left(1-\frac{h}{b}\right)=\rho_{2} w_{2} \\
& p_{t}+\rho_{t} w_{t}^{2}\left(1-\frac{h}{b}\right)=p_{2}+\rho_{2} w_{2} \\
& \rho_{t} w_{1}\left(1-\frac{h}{b}\right)(\gamma-1) H_{1}=\left(p_{2} w_{2}+\frac{\gamma-1}{2} \rho_{2} w_{2}^{3}\right)
\end{aligned}
$$

where $\mathrm{H}_{\mathrm{t}}=\frac{\mathrm{a}^{2}}{\gamma-1}+\frac{\mathrm{w}^{2}}{2}$, and $a$ is the local speed of sound. The shear stress at the walls is assumed negligible and the flow is considered isentropic in region 1. Thus, if absolute stagnation conditions, wheel speed, duct angle $\beta$, and static pressure $p_{1}$ are known in region 1 of Fig. 2, then Eqns. 3-6 may be used to find conditions in region 2 . 


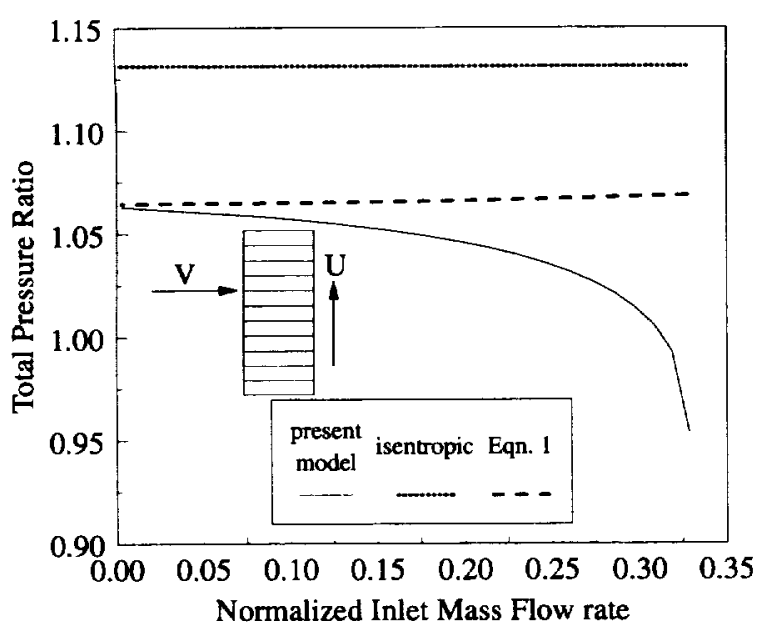

Figure 4 Calculated Flat Plate Compressor Performance Using Different Models.

Figure 3 compares the measured cascade loss coefficient for a sharp nosed turbine blade ${ }^{7}$ with that calculated from the present model at two inlet Mach numbers. The actual inlet Mach number of the data is not known. The loss coefficient is defined as

$$
\mathrm{K}=\frac{\Delta \mathrm{P}^{0}}{\frac{1}{2} \rho_{1} \mathrm{w}^{2}}
$$

The model shows fairly good agreement with the data at low incident Mach numbers, which simply means that Eqn. 1 is a reasonable low speed model. There is however, a strong incident Mach number dependence which has been pointed out by Lieblein ${ }^{8}$ for compressor cascades, and by Wilson for actual wave rotor flows. ${ }^{5}$ This is true even if a more appropriate loss coefficient is used such as

$$
\mathrm{K}=\frac{\Delta \mathrm{P}^{0}}{\left(\mathrm{P}_{1}^{0}-\mathrm{p}_{1}\right)}
$$

Since the modeled flow in region 1 up to the throat is assumed compressible, it is possible for choking to occur. Once choked flow is established Eqn. 5 is assumed invalid because, in keeping with the backward facing step analogy, the base pressure is not the same as the throat pressure. Equations. 4 and 6 remain correct however, with the left hand quantities fixed and known. This means that all downstream (region 2) flow quantities are known if a value of $p_{2}$ is chosen. This fact is significant when implementation of the model in a CFD code is discussed in a later section.

\section{Flat Plate Compressor}

Before discussing implementation in a wave rotor simulation however, it is worth examining the model predictions applied to a so-called 'flat plate compressor. That is, a single compression stage composed of axially aligned parallel channels and having axially aligned inlet flow. It would be expected that, while performance would be poor, some compression would be obtained. Furthermore, performance should be qualitatively similar to any compression or fan stage, namely, for a given wheel speed, the pressure ratio decreases with increasing flow rate. Figure 4 shows the absolute stagnation pressure ratio versus normalized inlet mass flow rate (i.e. $\frac{\dot{\mathrm{m}}_{\mathrm{i}}}{\rho^{*} \mathrm{a}^{*} \mathrm{~A}_{\mathrm{i}}}$ ) for a normalized wheel speed, $\frac{U}{a^{*}}=0.3$. The three curves represent performance calculated isentropically, with Eqn. 1, and with the present model, Eqns. 3-6. The curve representing the present model follows the expected trend. Of course, there are alternate explanations as to why a pumping characteristic follows the trend shown in Fig.4. It is at least encouraging however, that the incidence model is consistent.

\section{Model Implementation}

The incidence model described above was implemented in a CFD based, one-dimensional wave rotor simulation. Details of this simulation have been presented in the literature and as such, will not be described here. ${ }^{4,-11}$ The relevant feature for this discussion is that it numerically integrates the Euler equations with source terms accounting for viscous, heat transfer, and leakage effects. Like most solvers of this type, specific information is required at the computational boundaries. This is often accomplished by specifying a state for a fictitious 'image cell' lying conceptually just outside of the computing domain. Incorporating the incidence model into the boundary conditions is an iterative process which is described below. A flow chart description of the process is shown in Fig. 5.

In a given inlet duct, the total pressure, temperature, and flow angle are assumed known. The wheel speed of the rotor is also assumed known. An initial guess is made for the static pressure, $p_{1}$ at the duct exit. Since the flow in the duct is assumed isentropic and parallel to the walls, everything about the duct flow is known (e.g. velocity, density, temperature) for this particular static pressure. 


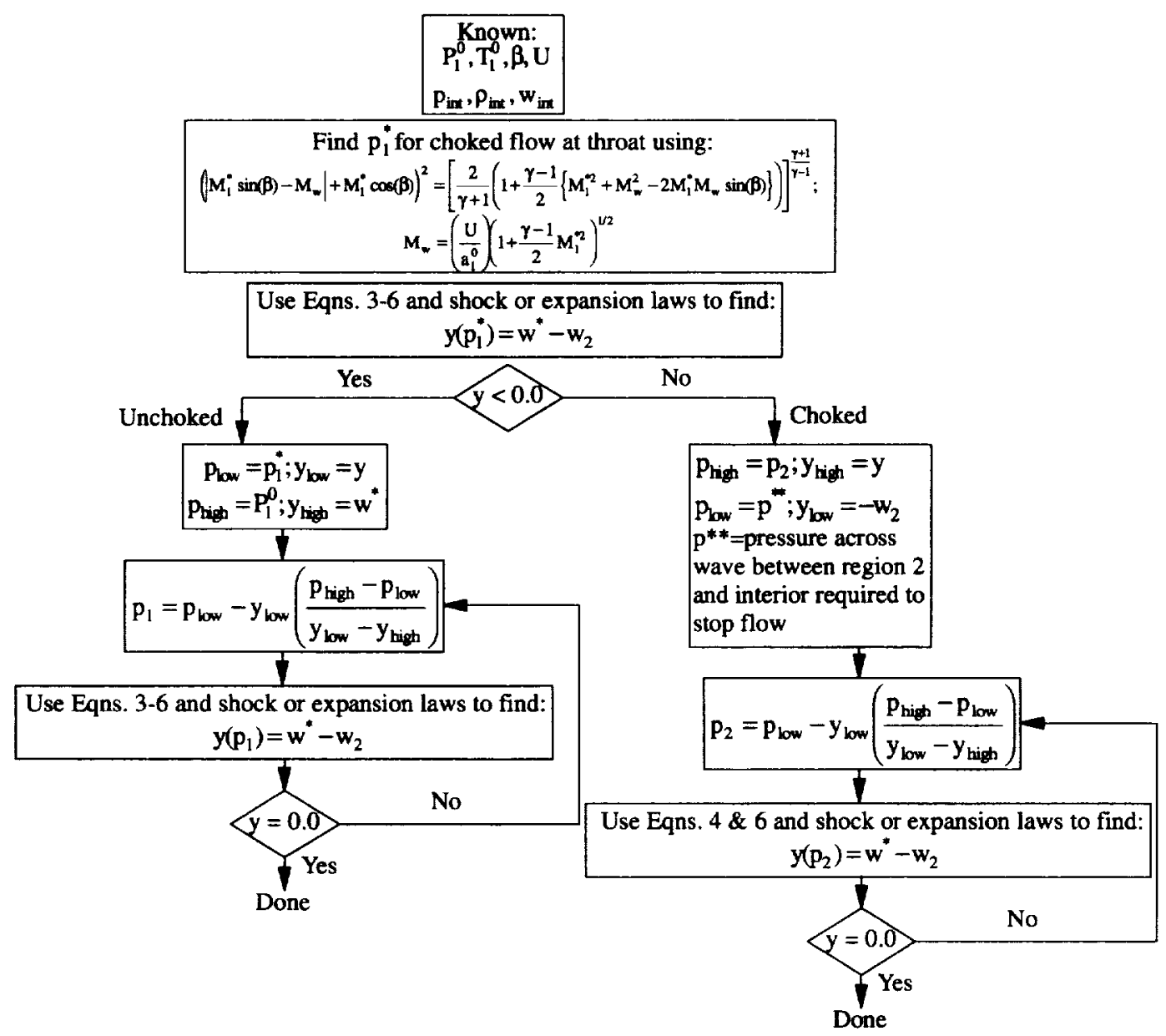

Figure 5 Flow Chart for Implementation of Incidence Model in the NASA 1-D Wave Rotor Simulation.

With the duct flow conditions known, Eqn. 3 may be used to calculate the vena contracta height, $h$. Under the assumption of isentropic flow from region 1 to the throat region $t$ of Fig. 2, the left side of Eqns. 4-6 may then be calculated. This results in three equation with three unkowns, $p_{2}, \rho_{2}$ and $w_{2}$, thus allowing these quantities to be obtained.

The assumed separation, turning, and mixing process is implemented in the image cell of the computing domain. Thus, the image cell is assigned the state 2 just calculated. Assuming flow from left to right, the first interior computational cell, denoted henceforth with the subscript int., is positioned immediately to the right of the image cell. The current state of the first interior cell is known. This state is not, in general, the same as that in the image cell and thus, a compression or expansion wave is established between the two cells. With the known interior cell gas state, and the known pressure $p_{2}$, in the image cell, the velocity across this wave, $u^{*}$ may be calculated using shock laws or isentropic relations. This should be the velocity in the image cell. In other words, if the initial guess at $p_{1}$ was correct, then $u_{2}=u^{*}$. If $u_{2} \neq u^{*}$, then another guess must be made for $p_{1}$.

The process is easily accomplished by establishing a function $y\left(p_{1}\right)=w^{*}-w_{2}$ and using a numerical root finding technique such as the false point method to find $y=0$. These techniques typically require initial values which bound the function. That is values $\mathrm{p}_{1}^{+}$and $\mathrm{p}_{1}^{-}$which yield positive and negative values of $\mathrm{y}$ respectively. A good choice for $\mathrm{p}_{1}^{+}$is the known absolute total pressure in the duct. The value of $\mathrm{p}_{1}^{-}$should be that static pressure which yields Mach 1.0 flow in plane $t$ of Fig. 2. If this value does not yield a negative value of $y$, then the flow is assumed choked in the separated region.

At this point, the left sides of Eqns. 4 and 6 become fixed. A guess is made at $p 2$ thus yielding $\rho_{2}$ and $u_{2}$. The value of $w^{*}$ may also be found so that a new function $q\left(p_{2}\right)=w^{*}-w_{2}$ may be defined and solved for 


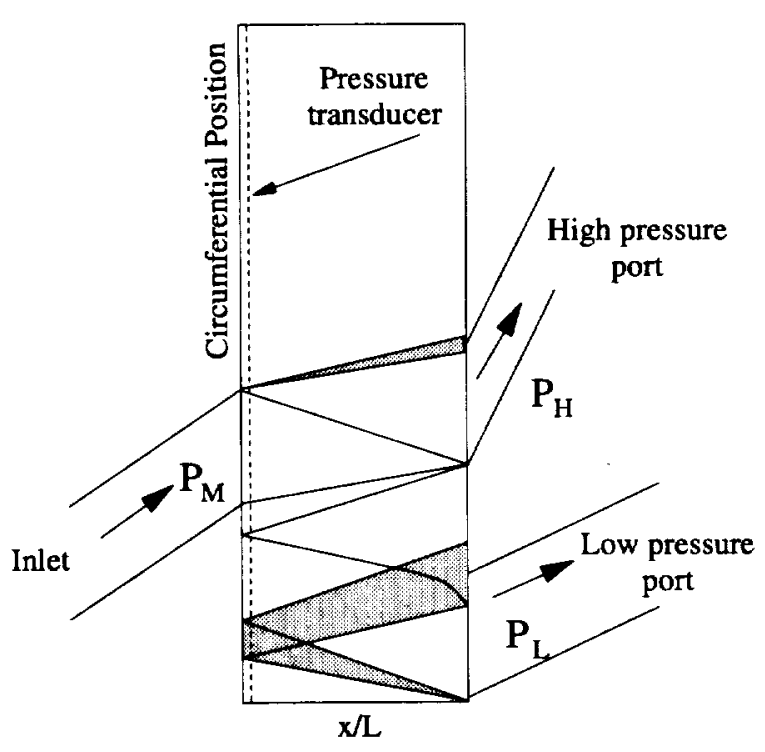

Figure 6 NASA 3-Port Wave Rotor Experiment Cycle.

the choked condition in precisely the same manner as $y\left(p_{1}\right)$.

Results and Comparison With Experiment

The NASA 3-Port wave rotor experiment ${ }^{5}$ was used as a basis for evaluating the present incidence model. The reasons for this are twofold. First, there is a plethora of data available from the experiment. Second, the design was such that large incidence angles at relatively high relative Mach numbers were observed. The experiment was a so-called divider cycle in which flow is brought on board the rotor at an intermediate pressure and is split by the gasdynamic waves. A portion of the flow exits through one port at a higher pressure than the inlet, a portion exits through another port at a lower pressure than the inlet. The cycle is shown in Fig. 6 as an $x-t$ diagram.

Several rotor configurations were tested in the experiment using the same wave cycle. The results to be presented here are from the rotor which was $22.9 \mathrm{~cm}$. long, $30.5 \mathrm{~cm}$. in diameter, having passages $1.0 \mathrm{~cm}$. high, and a $0.6 \mathrm{~cm}$ wide. The rotor spun at a constant $7400 \mathrm{rpm}$. Inlet stagnation pressure and temperature were maintained at $0.21 \mathrm{MPa}$. and $322 \mathrm{~K}$, respectively. The ratio of high pressure port mass flow to inlet mass flow, $\xi$ was maintained at approximately 0.37 .

The geometry of the inlet duct was such that, with reference to Fig. 6, the lower wall possessed significant curvature. The actual geometry is shown in Fig. 7. Flow angle measurements were made in the plane shown and curve-fit to create the estimated flow angle

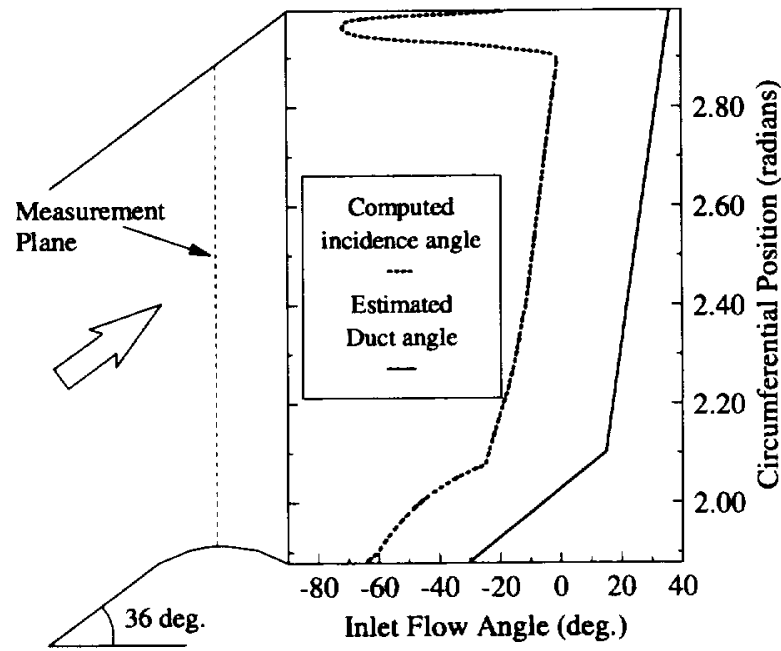

Figure 7 Inlet Geometry and Assumed Flow Angle of the NASA 3-Port Wave Rotor.

(representing $\beta$ in Fig. 1) shown in the figure. Also shown in Fig. 7 is the computed distribution of incidence angle for one operating point.

It is noted that in this experiment, like most, other loss mechanisms were present, and it was not possible to isolate one from another. Similarly, the simulation contains loss models for leakage, friction, and finite passage opening time among others, and all of these interact. It is possible that within the experiment, and within the simulation, two different loss mechanisms can manifest the same overall behavior. The fact that the NASA experiment was so highly instrumented however, did help to delineate the various effects. Nevertheless, Wilson ${ }^{5}$ concluded that it was not possible to interpret the experimental results without including incidence loss

Figure 8 shows the measured and computed performance of the NASA wave rotor using various incidence loss models. For all of the simulation results to be presented, a numerical cell spacing of $\Delta x / L=0.02$ was used with an associated time step of $\Delta \mathrm{ta}^{*} / \mathrm{L}=0.008$. For each operating point the simulation was run until the total mass flow rate from the exit ports matched that of the inlet port. With reference to Fig. 6, the plot shows the ratio of high to medium total pressure versus the ratio of low to medium total pressure.

The leakage and finite opening time loss models of the simulation do not have adjustable parameters; however, the viscous model (a source term in the momentum equation) does. In particular, the momentum equation of the simulation has the non-dimensional form: 


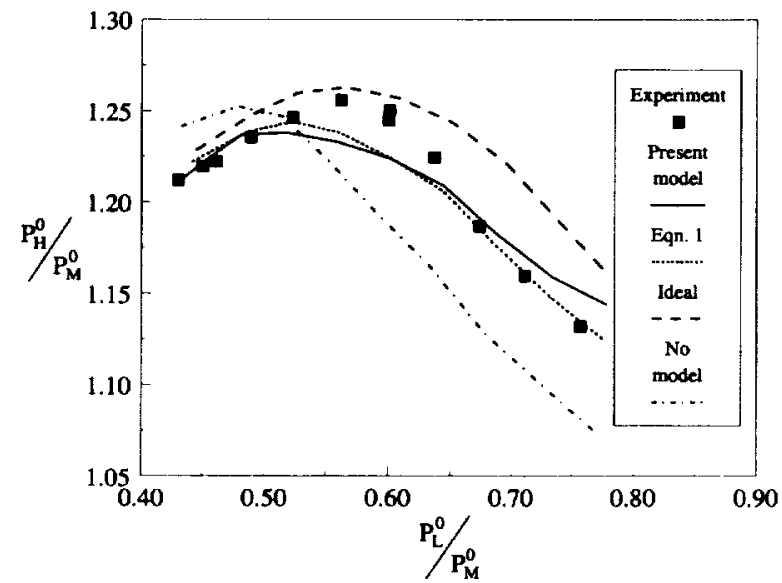

Figure 8 Computed and Measured Performance of the NASA 3-Port Wave Rotor.

$$
\frac{\partial}{\partial \tau}\left(\rho^{\prime} w^{\prime}\right)+\frac{\partial}{\partial x^{\prime}}\left(\frac{p^{\prime}}{\gamma}+\rho^{\prime} w^{\prime 2}\right)=-\sigma w^{\prime}\left|\rho^{\prime} w^{\prime}\right|^{0.75}(9)
$$

For each of the incidence models shown in Fig. 8, the viscous source term coefficient $\sigma$ was adjusted until the mass flow ratio $\xi=0.37$ was obtained subject to the experimental port boundary conditions corresponding to the point furthest to the left in the figure (the design point). For all other points in the figure, the coefficient was then fixed. It is noted that this procedure also had the effect of closely matching the mass flow through the wave rotor for all of the incidence models examined. An exception to this procedure was made for the line labeled 'no incidence model'. This calculation was obtained by assuming flow entirely in the relative reference frame, and always aligned with the passage. For exit ports, which utilize static pressure to specify boundary conditions, nothing is changed by this assumption. For inflow ports, which utilize stagnation conditions at the boundaries, relative values were estimated from the measured absolute conditions, rotor speed, mass flow rate, and duct angle at the high mass flow rate operating point (far left of Fig. 8).

It is clear from Fig. 8 that (assuming other aspects of the simulation are correct) some form of incidence model is needed in order to accurately predict the wave rotor performance. The simulation results with no incidence model are not only incorrect in magnitude, but in trend, which is arguably much more important.

The line indicated as ideal in the figure was generated by assuming a loss free turning of the incident flow. This is obviously not physically correct as shown by the large performance enhancement toward the right of the plot; however, it serves the purpose of bounding the

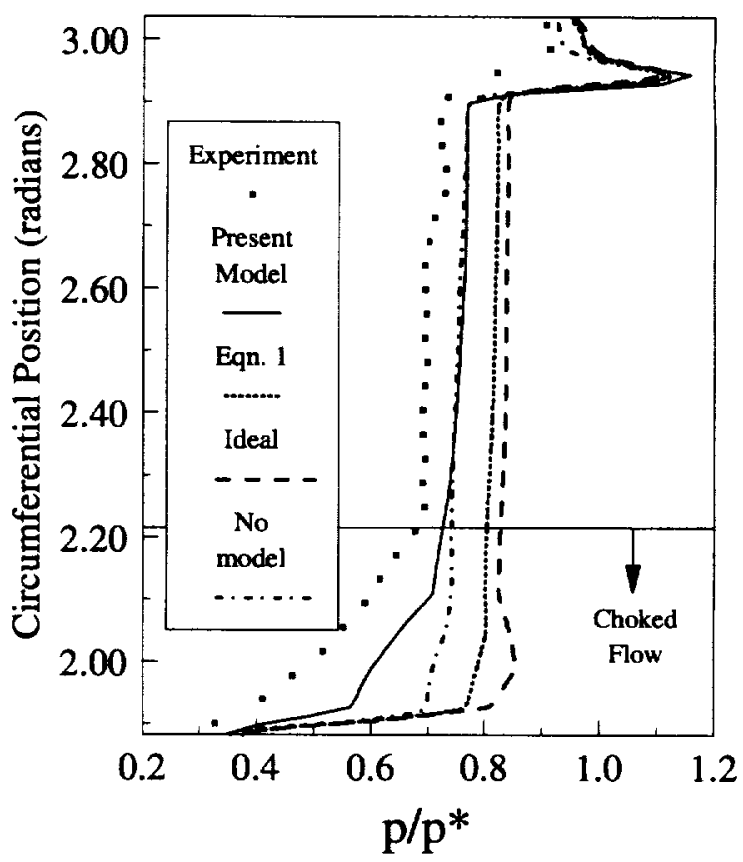

Figure 9 Computed and Measured Static Pressure In the Inlet Region at $\mathbf{x} / \mathbf{L}=\mathbf{0 . 0 2 5}$ for the Far Left Point in Fig. 8 of the NASA 3-Port Wave Rotor.

limit of incidence effect for this particular experiment.

The predicted performance using Eqn. 1 and the present model appear to predict very similar performance. It should be noted however, that the calculations using Eqn. 1 required a viscous source term coefficient 1.59 times that used for the present model in order to match $\xi$ at the experimental boundary conditions. In other words, the viscous losses were increased to compensate for the reduced incidence losses. The same compensation was required with the 'ideal' incidence model. Here however, the viscous source term coefficient was 1.78 times that used in the present model

The consequences of this compensation are large when the simulation is extended to predict the performance of other wave rotor cycles. Using the Eqn. 1 incidence model, results from the NASA 3-Port Experiment, and a procedure outlined in Ref. 11, a scaling law for the viscous source term coefficient may be obtained which can be used to predict the performance of other wave rotor geometries and cycles. When this was done, it was found that a four-port wave rotor used as a topping cycle on a small helicopter engine drops in design point performance from an overall pressure ratio of 1.20 to 1.16. This result underscores the large; albeit indirect influence of incidence loss models on performance predictions of wave rotor cycles of interest. 


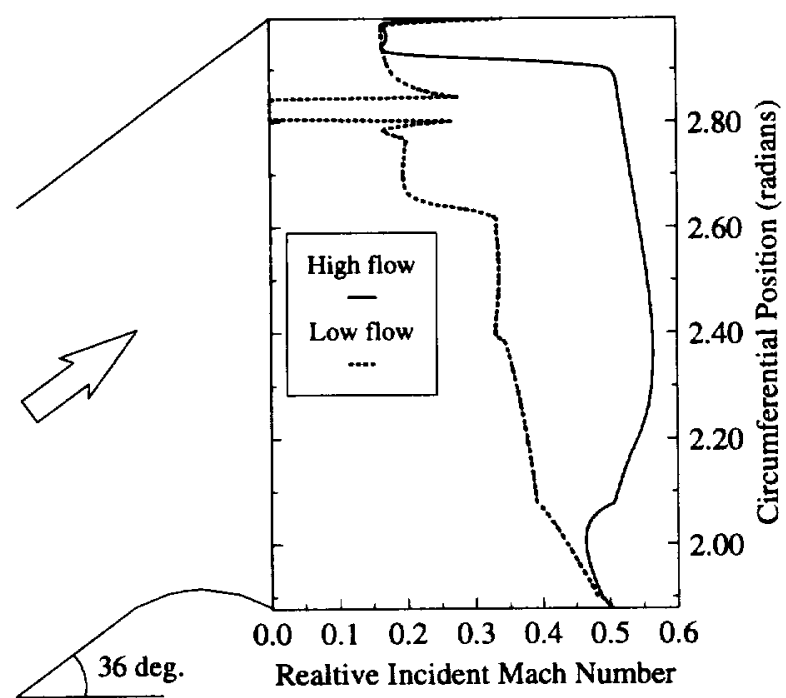

Figure 10 Computed Distribution of Inlet Incident Mach Number for Two OPerating Points of the NASA 3-Port Wave Rotor.

Figure 9 shows circumferential distributions of computed and measured static pressure in the inlet region, at $x / L=0.025$, for the operating point corresponding to the far left of the curves in Fig. 8, using the same incidence models as those of Fig. 8. Of particular interest is the lower third of the figure. In this region, the present model predicted a choked flow situation with the accompanying large losses. The shape of the curve using the present model matches the data to a reasonable degree, which cannot be said for any of the other incidence models. This observation may lend credence to the present incidence modeling approach. It should be kept in mind however, that there are numerous other explanations for the shape of the pressure profile in Fig. 9, not the least of which are two and three-dimensional effects not resolved by the simulation. Furthermore, the region shown as choked in Fig. 9 temporally represents only about $70 \%$ of the time required for a wave to travel down the passage. It is not clear that steady state incidence models, as described here, are even appropriate. Nevertheless, the agreement is encouraging.

The computed distribution of incident Mach number in the inlet is shown in Fig. 10 for two different operating points. The solid line corresponds to the high mass flow rate design point (far left of Fig. 8), while the dashed line corresponds to a low mass flow operating point (far right of Fig. 8). The portion of the low flow curve showing zero relative Mach number densotes a region of computed outflow in the inlet port. The purpose of the figure is simply to indicate the incident

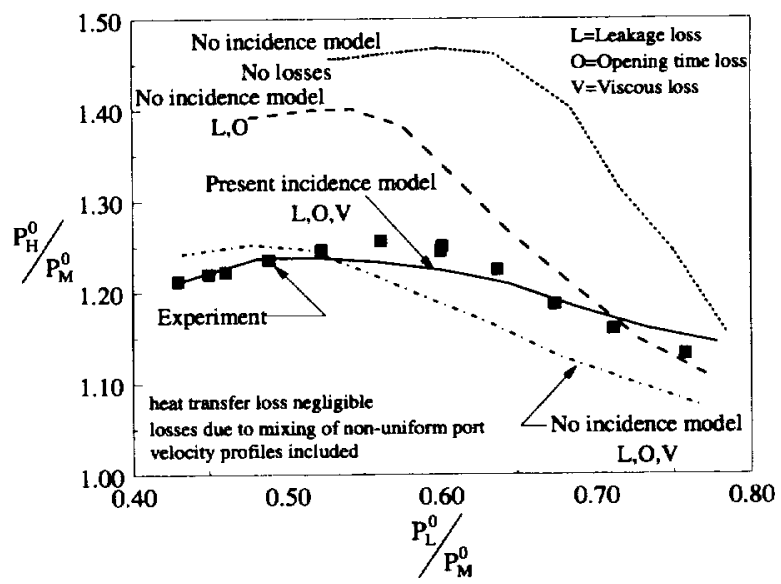

Figure 11 Comparison of Loss Mechanisms in the NASA 3-Port Wave Rotor.

Mach number range to which passages are exposed in this experiment.

\section{Comparison of Loss Mechanisms}

Although not presented in this paper, the simulation used in this investigation contains models for other loss mechanisms associated with wave rotors. These include losses due to leakage from passage ends to and from the casing, viscosity (e.g. wall shear stress), finite passage opening time, mixing of non-uniform port velocity profiles, and heat transfer. It is worthwhile to examine the losses (or effects) due to incidence in comparison to the others. For the experimental results presented, the losses due to heat transfer and finite passage opening time are considered negligible. Figure 11 shows the same performance curve as that shown in Fig. 8 with the various loss mechanisms 'turned on' or 'off'. Nonuniform velocity profile mixing loss calculations were included for all of the computational results.

It can be seen that viscous and leakage losses predominate over most of the performance curve. In the low mass flow region however (to the right of the figure, far from the design point) the effect of incidence is relatively large and actually shows an improvement in performance. This is likely because, although the incidence is large, the 'flat plate compressor' effect is still doing useful work on the flow. This is also true at operating points in the left of the figure, however, at these points, the inlet flow on which the work is done exits through the low pressure port. In the low flow right hand region of the figure the inlet flow on which the work is done exits through the high pressure port. These flow paths are illustrated with dashed lines on the $x-t$ diagrams shown in Fig. 12. 

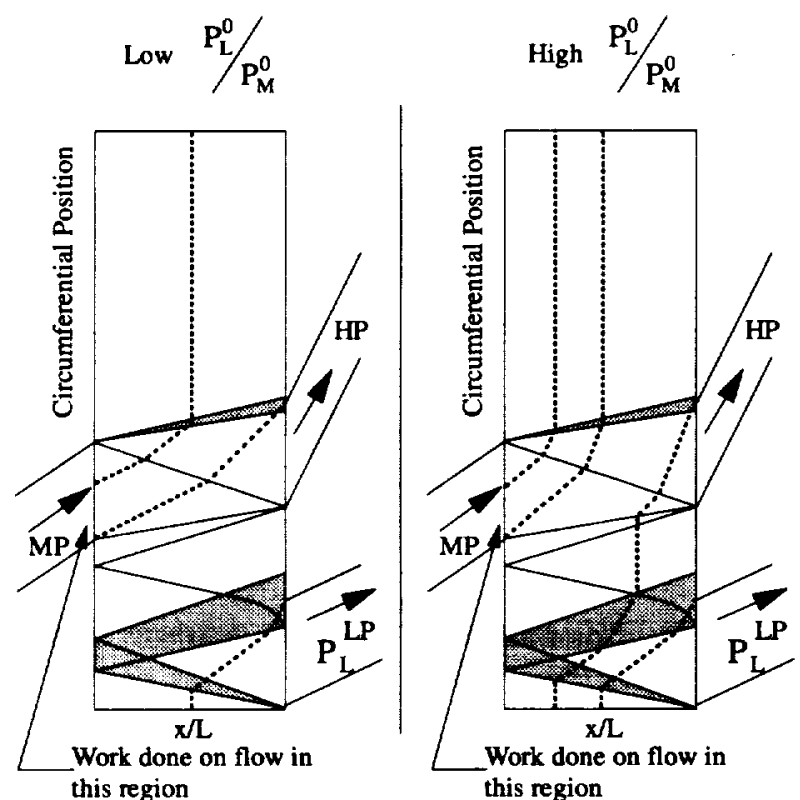

Figure 12 X-t Diagrams Ilustrating Particle Paths for Different Operating Points of the NASA 3-Port Wave Rotor.

\section{Conclusions}

A simple incidence loss model for wave rotors with axially aligned passages has been presented. The model shows losses which depend on both incident Mach number and flow angle. When implemented in a onedimensional CFD wave rotor simulation, the model predictions are consistent with experimental measurements made on a 3-port Divider Cycle rig. This includes favorable comparison with overall performance data and on-board static pressure measurements in a high incidence inflow region. It has also been shown that several other modeling approaches fall short when compared to experimental data.

\section{References}

1. Welch, G. E. , "Two-Dimensional Computational Model for Wave Rotor Flow Dynamics", ASME Paper 96-GT-550, June 1996 (also NASA. TM 107192).

2. Lear, W. E., Candler, G. V., "Direct Boundary Value Solutions for Wave Rotor Flowfields," AIAA 93-0483, January, 1993.

3. Paxson, D. E. and Lindau, J. W., "Numerical Assessment of Four-Port, Through-Flow Wave Rotor Cycles With Passage Height Variation," AIAA paper 97-3143, July, 1997, also NASA TM 107490.

4. Paxson, D. E., "A Comparison Between Numerically Modelled and Experimentally Measured Loss Mechanisms in Wave Rotors," AIAA Journal of Propulsion and Power, Vol. 11,
No. 5, 1995, pp. 908-914, (also NASA TM 106279).

5. Wilson, J., "An Experiment on Losses in a 3-Port Wave Rotor", NASA Contractor Report, CR198508, 1997.

6. Roelke, R. J., "Miscellaneous Losses," Chapter 8 of Turbine Design and Applications, NASA SP290, Glassman, A. J., ed., 1994.

7. Emmert, H. D., "Current Design Practices for Gas Turbines Power Elements", Transaction of the ASME, Vol. 72, pp. 189-200, 1950.

8. Lieblein, S., "Experimental Flow in TwoDimensional Cascades," Chapter VI of Aerodynamic Design of Axial Flow Compressors, NASA SP-36, Johnson, I. A., ed., 1965.

9. Paxson, D. E., "A General Numerical Model for Wave Rotor Analysis," NASA TM 105740, July,1992.

10. Paxson, D. E., "Numerical Simulation of Dynamic Wave Rotor performance," AIAA Joumal of Propulsion and Power, Vol. 12, No. 5, 1996, pp. 949-957, (also, NASA TM 106997).

11. Paxson, D. E. , Wilson, J., "Recent Improvements to and Validation of the One Dimensional NASA Wave Rotor Model," NASA TM 106913, May, 1995. 



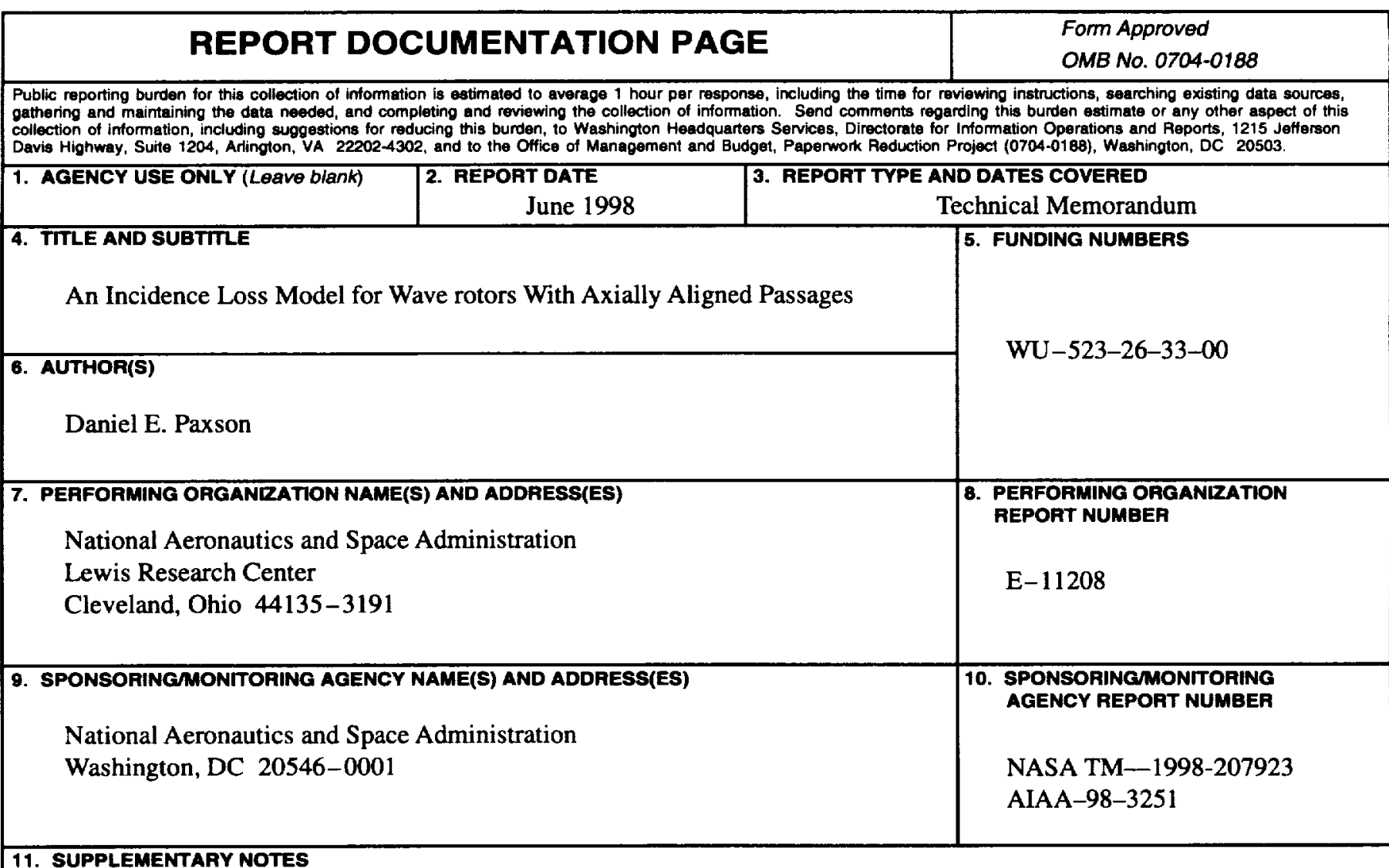

\section{SUPPLEMENTARY NOTES}

Prepared for the 34th Joint Propulsion Conference cosponsored by AIAA, ASME, SAE, and ASEE, Cleveland, Ohio, July 12-15, 1998. Responsible person, Daniel E. Paxson, organization code 5530, (216) 433-8334.

12a. DISTAIBUTION/AVAILABILITY STATEMENT

Unclassified - Unlimited

Subject Categories: 07 and 34 12b. DISTRIBUTION CODE

This publication is available from the NASA Center for AeroSpace Information, (301) 621-0390.

\section{ABSTRA $-T$ (Maximum 200 words)}

A simple mathematical model is described to account for the losses incurred when the flow in the duct (port) of a wave rotor is not aligned with the passages. The model, specifically for wave rotors with axially aligned passages, describes a loss mechanism which is sensitive to incident flow angle and Mach number. Implementation of the model in a one-dimensional CFD based wave rotor simulation is presented. Comparisons with limited experimental results are consistent with the model. Sensitivity studies are presented which highlight the significance of the incidence loss relative to other loss mechanisms in the wave rotor.

\begin{tabular}{|c|c|c|}
\hline \multicolumn{3}{|c|}{$\begin{array}{l}\text { 14. SUBJECT TERMS } \\
\text { Wave rotor; Computational Fluid Dynamics (CFD) }\end{array}$} \\
\hline $\begin{array}{l}\text { 17. SECURTY CLASSIFICATION } \\
\text { OF REPORT } \\
\text { Unclassified }\end{array}$ & $\begin{array}{l}\text { 18. SECURITY CLASSIFICATION } \\
\text { OF THIS PAGE } \\
\text { Unclassified }\end{array}$ & $\begin{array}{l}\text { 19. SECURITY CLASSIFICATION } \\
\text { OF ABSTRACT } \\
\text { Unclassified }\end{array}$ \\
\hline
\end{tabular}

NSN 7540-01-280-5500 